\title{
Pharmacokinetics of Tolmetin with and without Concomitant Administration of Antacid in Man*
}

\author{
J. W. Ayres ${ }^{2}$, D. J. Weidler ${ }^{1}$, J. MacKichan ${ }^{1}$, E. Sakmar ${ }^{1}$, M. R. Hallmark ${ }^{1}$, \\ E.F. Lemanowicz ${ }^{3}$ and J. G. Wagner** \\ ${ }^{1}$ College of Pharmacy and Upjohn Center for Clinical Pharmacology, The University of Michigan, Ann Arbor, Michigan 48109, USA \\ ${ }^{2}$ School of Pharmacy, Oregon State University, Corvallis, Oregon 97331, USA \\ ${ }^{3}$ McNeil Laboratories, Inc., Fort Washington, Pennsylvania 19034, USA
}

Summary. The purpose of this study was to determine whether a concomitant single dose of antacid or multiple doses of antacid administered prior to, and with tolmetin, alter the pharmacokinetics of tolmetin when the drug was administered as a commercially available tablet ${ }^{2}$ containing tolmetin sodium. The possible effects of the antacid on plasma concentrations and urinary excretion of tolmetin and its major metabolite were evaluated following administration of: (a) tolmetin sodium alone; (b) antacid four time a day for three days prior to a single dose of tolmetin sodium, with continuation of the antacid during the day tolmetin was given; and (c) co-administration of single doses of tolmetin sodium and antacid. The twenty-four subject study was of the crossover type. There were no significant differences among treatment means for: (i) peak plasma concentrations of both tolmetin and metabolite, (ii) AUC $0-8 \mathrm{~h}$ and AUC $0-x$ for both tolmetin and metabolite, (iii) time to peak plasma concentration for both tolmetin and metabolite, (iv) plasma concentrations of both tolmetin and the metabolite at all sampling times (except for tolmetin at $2 \mathrm{~h}$ ), (v) renal clearance of both tolmetin and its metabolite, and (vi) the amount of metabolite excreted in the $0-24 \mathrm{~h}$ urine. There were small, but significant, differences among amounts of tolmetin excreted in the $0-24 \mathrm{~h}$ urine. Semilogarithmic plots of both tolmetin and metabolite plasma concentrations past the peak concentrations were curved over the entire 8-h observation period; although the elimination half-life of tolmetin has been reported

\footnotetext{
* Supported by a contract from McNeil Laboratories, Inc.

** Please address reprint requests to: Dr. John G. Wagner, Upjohn Center for Clinical Pharmacology, The University of Michigan Medical Center, Ann Arbor, Michigan 48109, USA.

1 Maalox $^{\circledR}$ (William H. Rorer, Inc.).

2 Tolectin $^{3}$ (McNeil Laboratories, Inc.).
}

to be about one hour, the half-life most probably exceeds $2.6 \mathrm{~h}$ in most subjects. The results of this study indicate a lack of a significant drug-drug interaction between the non-steroidal anti-inflammatory agent, tolmetin sodium, and a commonly used antacid, which is a mixture of magnesium and aluminium hydroxides.

Key words: Tolmetin, pharmacokinetics, bioavailability, antacid, oral dose.

Tolmetin (1-methyl-5-p-toluoylpyrrole-2-acetic acid) is an anti-inflammatory drug recommended for the relief of the signs and symptoms of rheumatoid arthritis. The chemistry (Carson et al., 1971) and pharmacology (Wong et al., 1973) have been reported, and the major metabolite [5-(p-carboxybenzoyl)-1-methypyrrole-2-acetic acid] has been isolated from the urine (Sumner et al., 1975; Plostnieks et al., 1975). The pharmacokinetics of tolmetin have been studied in normal subjects (Plostnieks et al., 1975; Cressman et al., 1975; Selley et al., 1974; Selley et al., 1975) and the mean elimination half-life was reported as about $1.0 \mathrm{~h}$. The mean elimination half-life was reported to be between 0.83 and $1.0 \mathrm{~h}$ in arthritic patients (Plostnieks et al., 1975; Selley et al., 1974; Selley et al., 1975).

Antacids are widely used drugs which might be taken by patients along with tolmetin, either with or without the knowledge of the attending physician. It is well established that some antacids can affect the gastrointestinal absorption of drugs via complexation, adsorption, or modification of the percent of drug ionized in the gastrointestinal tract, because of changes of gastrointestinal $\mathrm{pH}$. Drugs whose rate or extent of absorption have been affected by antacids 
Table 1. Study design for three treatment crossover with 24 subjects and six treatment sequences with details of treatments

\begin{tabular}{lllll}
\hline \multirow{5}{*}{ Group } & Subject number & Week I & Week II & Week III \\
\cline { 3 - 5 } & & Treatment & \\
I & $3,9,15,22$ & A & B & C \\
II & $1,11,13,20$ & C & A & B \\
III & $2,12,14,21$ & B & C & A \\
IV & $4,7,16,24$ & A & C & B \\
V & $5,8,17,23$ & B & A & C \\
VI & $6,10,18,19$ & C & B & A \\
\hline
\end{tabular}

Treatment A: $400 \mathrm{mg}$ of tolmetin sodium as two (2) Tolectin ${ }^{(3)}$ (tolmetin sodium $200 \mathrm{mg}$ ) tablets administered with $200 \mathrm{ml}$ of water.

Treatment B: On each of the three days preceding drug administration the subjects received a $20 \mathrm{ml}$ dose of Maalox ${ }^{\circledR}$ magnesium and aluminium hydroxides suspension four times per day at 8:00 a. m., 1:00 p. m. $, 6: 00$ p.m. and 11:00 p. m. The container was rinsed two times with $20 \mathrm{ml}$ volumes of water and the contents consumed each time. On the day of dosing, immediately following the 8:00 a.m. antacid administration, $400 \mathrm{mg}$ of tolmetin sodium as two (2) tolectin (tolmetin sodium $200 \mathrm{mg}$ tablets) were administered with $140 \mathrm{ml}$ of water. Antacid was administered during the remainder of the dosing day as above.

Treatment C: $20 \mathrm{ml}$ of Maalox magnesium and aluminium hydroxides suspension were administered and the container rinsed two times with $20 \mathrm{ml}$ volumes of water and the contents consumed each time. Immediately thereafter $400 \mathrm{mg}$ of tolmetin sodium as two (2) Tolectin tablets (tolmetin sodium $200 \mathrm{mg}$ tablets) were administered with $140 \mathrm{ml}$ of water.

include (but are not limited to) propantheline (Herxheimer and Chaput de Saintonge, 1973), bishydroxycoumarin (Ambre and Fisher, 1973) and aspirin (Lieberman and Wood, 1964). In addition, antacids may affect urinary pH (Gibaldi et al., 1974; Gibaldi et al., 1975) and changes in urinary $\mathrm{pH}$ have been shown to affect the elimination half-life of such drugs as sulfonamides (Kostenbauder et al., 1962) and salicylates (Levy and Leonards, 1971).

A crossover study was performed with 24 normal volunteers during which plasma concentrations and urinary excretion of both tolmetin and its major metabolite were measured after administration of tolmetin with and without antacid. The pharmacokinetics of the drug and the major metabolite are discussed.

\section{Material and Methods}

Twenty-four male volunteers (aged 21-43 years; weight $66-89 \mathrm{~kg}$ ) in good health participated in the study. All subjects received a screening medical examination and a drug history was taken; 20 different blood and urine sceening tests were performed and all subjects were found to be within normal labora- tory limits for all tests. A three-treatment crossover study was performed utilizing all six possible treatment sequences, as shown in Table 1 .

All subjects selected received no other drugs than tolmetin and the antacid for a period of at least 14 days preceeding initiation of the study, nor until its completion. All subjects consumed a standard meal (no milk) on the evening prior to dosing, and then received no food or beverage, except water, for at least $12 \mathrm{~h}$ before the tolmetin doses and until at least four hours post dosing with tolmetin, at which time another standard meal (no milk) was consumed. Each dose of tolmetin consisted of two tablets $^{2}$ each containing the equivalent of $200 \mathrm{mg}$ of tolmetin as the sodium salt (see Table 1).

Seven $\mathrm{ml}$ blood samples were collected ${ }^{3}$ at 0,10 , $15,20,30,40,60$, and $90 \mathrm{~min}$ and $2,3,4,6$ and $8 \mathrm{~h}$ after dosing and the plasma was immediately harvested and frozen. Each subject voided his bladder immediately prior to the dose of tolmetin, and the 0 to $24 \mathrm{~h}$ urine was collected on the day of dosing and frozen until assayed.

All plasma samples were assayed for tolmetin and the major metabolite using high pressure liquid chromatography (Ayres et al., 1977). The same procedure was used for urine samples except that each urine sample was diluted $(1 \mathrm{ml}$ of urine plus $10 \mathrm{ml}$ of distilled water) prior to determining the metabolite, in order to keep the concentration in the range of the standard curve.

The study was run according to the study design in Table 1 with six treatment sequences and four subjects per treatment sequence. The computer program available for analysis could not do an analysis of variance (ANOVA) for this design. Therefore, for the computer-performed ANOVA's, three groups (rather than six) were assigned as follows: Group I consisting of subjects $3,4,7,9,15$, 16,22 and 24 who received treatment $A$ on week I; Group II consisting of subjects $2,5,8,12,14,17$, 21 and 23 who received treatment $B$ on week I; and Group III consisting of subjects $1,6,10,11,13,18$, 19 and 20 who received treatment $C$ on week $I$. This change meant that the "Group Mean Square" for the computer performed ANOVA did not mean "Treatment Sequence". The computer-performed ANOVA's were compared to the results of ANOVA's performed with a desk calculator according to the appropriate study design for some of the variables to see if the change in group assignments distorted the $F$ values and significance levels of the Treatment Mean Square of the computer-performed ANOVA's. The power of each ANOVA, calculated

\footnotetext{
3 Vacutainers ${ }^{\circledast}$ with sodium heparin, Bectin-Dickinson
} 


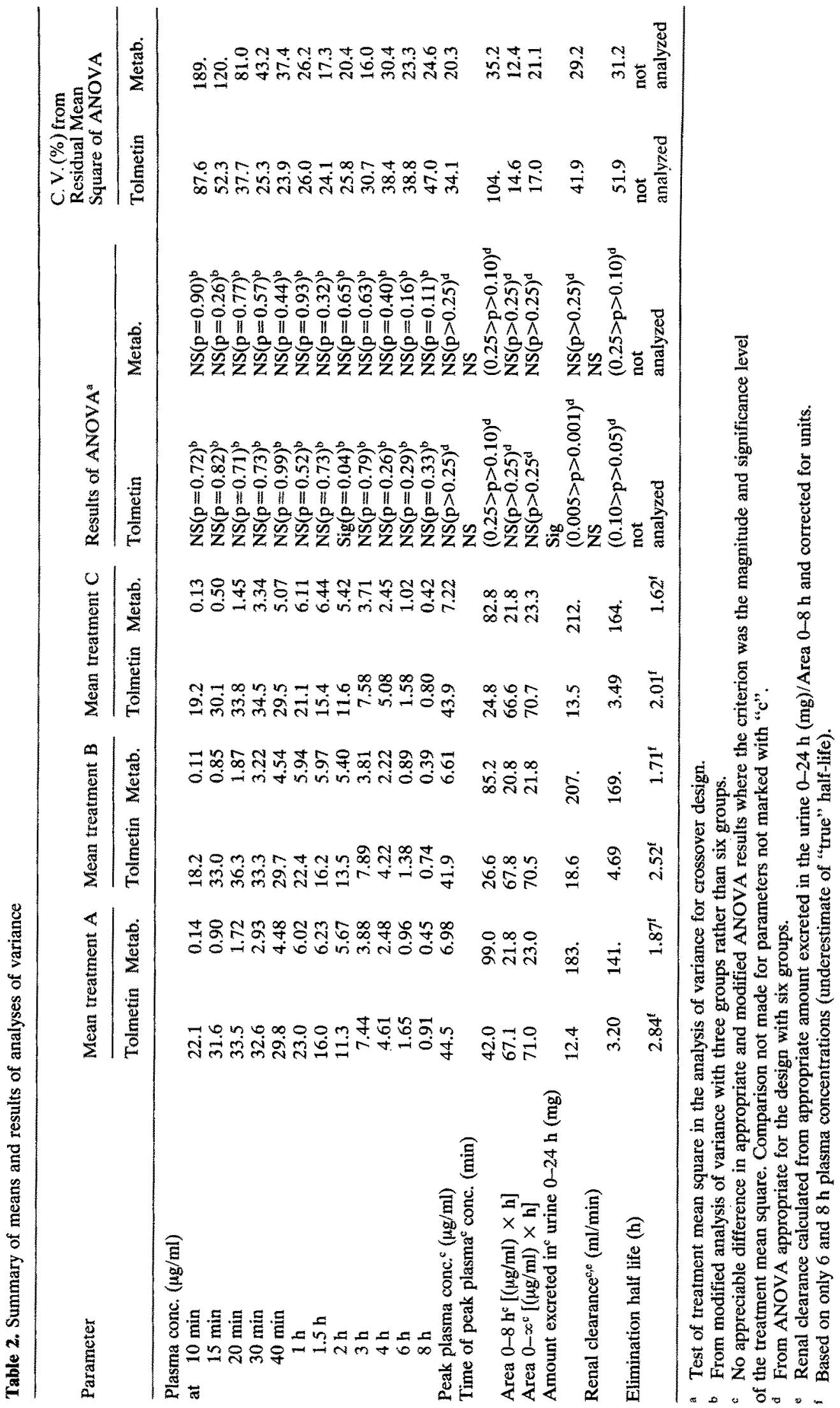



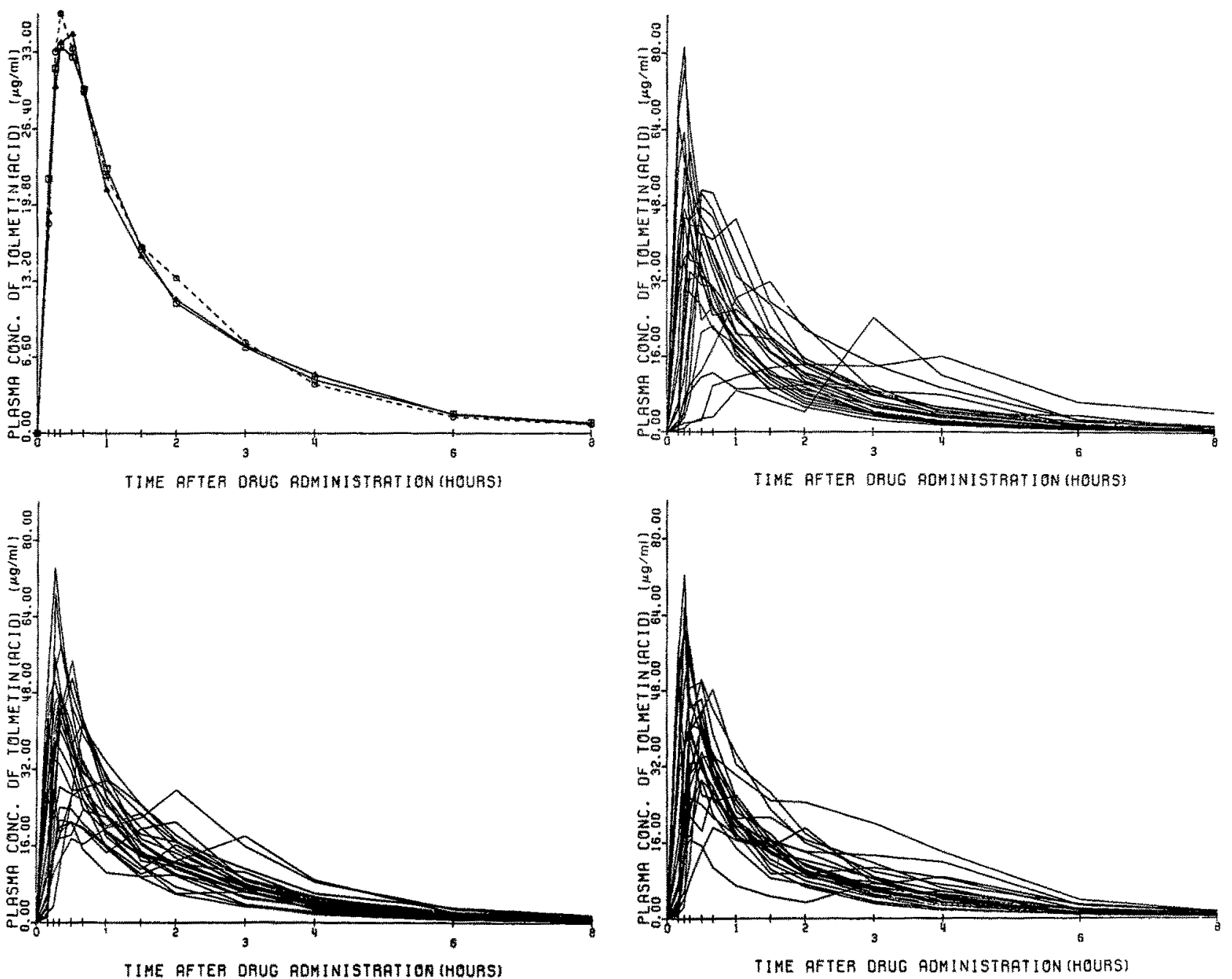

Fig. 1. Mean and individual plasma concentrations of tolmetin for all three treatments

from the residual mean square (RMS), for a given difference in extreme means was determined.

All plasma concentration, time data for tolmetin and its major metabolite and all urinary excretion data were analyzed pharmacokinetically. Area under the curve (AUC) values from 0 to $8 \mathrm{~h}$ were calculated using the trapezoidal rule. AUC $0-\infty$ values were estimated from: AUC 0-8 + (plasma concentration at $8 \mathrm{~h}$ ) $/ \beta$, where $\beta$ was estimated from the last two plasma concentrations (see Discussion). Renal clearance was calculated from the ratio: (amount excreted in the urine 0-24 h)/(AUC 0-8), which is, in this case, essentially equivalent to (amount excreted in the urine $0-\infty) /($ AUC $0-\infty)$.

\section{Results}

No adverse effects were observed following the three treatments. Table 2 summarizes the means and the results of ANOVA's for the major phar- macokinetic parameters following each treatment. In those cases where both types of ANOVA's were performed, there were no appreciable differences in the results obtained, when the criterion was the magnitude and significance level of the Treatment Mean Square. Table 2 shows that no significant differences were found among treatment averages for any of the parameters compared, except for the plasma concentrations of tolmetin at two hours.

Figure 1 shows the mean plasma concentrations of tolmetin as well as the individual subject plasma concentrations for all three treatments. Figure 2 shows the same type of information for the major metabolite of tolmetin. Figures 1 and 2 were computer generated. It is apparent without statistical analysis, that there was no effect of the antacid on mean tolmetin or metabolite levels. The statistical analysis strongly supports this viewpoint. The mean peak plasma concentrations of tolmetin were 44.5 , 41.9 , and $43.9 \mu \mathrm{g} / \mathrm{ml}$ for treatments A, B and C, respectively and the differences among means were 

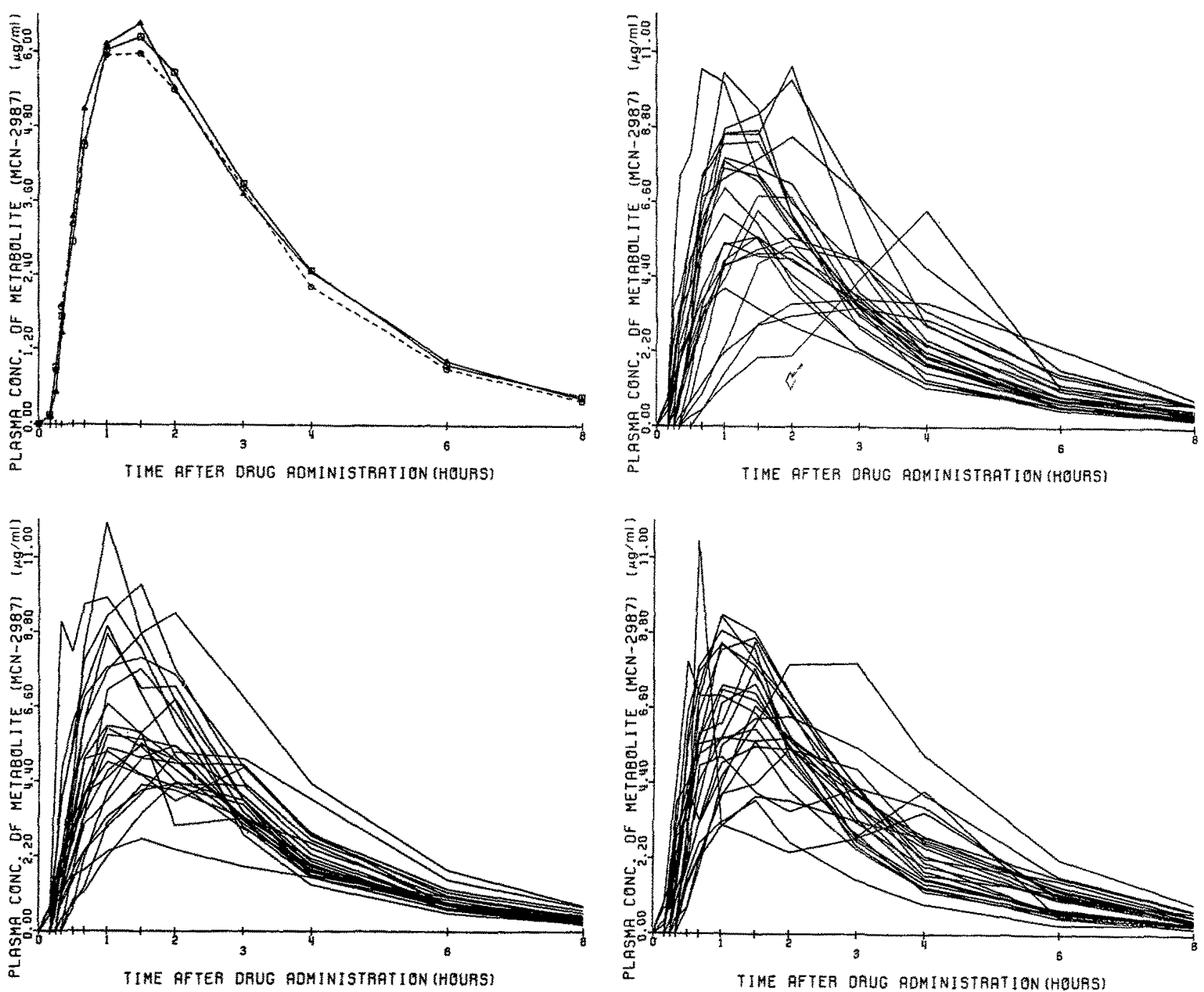

Fig. 2. Mean and individual plasma concentrations for the major metabolite of tolmetin for all three treatments

not significant ( $\mathrm{F}=0.26, \mathrm{p}>0.25)$. Week averages for mean peak plasma concentrations were 44.7 , 41.7 , and $43.9 \mu \mathrm{g} / \mathrm{ml}$ for weeks I-III, respectively, and the differences among the means were not significant $(F=0.20, p>0.25)$. The treatment sequences (groups) gave $F=0.68,(p>0.25)$. The coefficient of variation (C.V.), calculated from the RMS, was $34.1 \%$. The power of the ANOVA $(1-\beta)$ was 0.84 for a $30 \%$ difference in extreme means. Such results, along with the results in Table 2 , clearly show that the antacid did not produce any significant effects on tolmetin plasma levels.

Figures 3 and 4 show representative semilogarithmic plots of terminal plasma concentrations of tolmetin and its major metabolite, respectively. It is clear that each of these plots is curved and a true "log-linear or $\beta$ phase" has not yet been reached at the end of $8 \mathrm{~h}$ following oral dosing. $A$ "true half- life" cannot be obtained from such data, but a mean half-life of greater than $2.6 \mathrm{~h}$ for tolmetin and greater than $1.7 \mathrm{~h}$ for the metabolite can be estimated by considering only the 6 and $8 \mathrm{~h}$ concentrations of each compound for each subject (see Table 2).

Although there was no evidence of an effect of the antacid on plasma AUC or concentrations of either tolmetin or its major metabolite, the antacid did significantly alter the urinary excretion of tolmetin $(F=6.79,0.005>p>0.001)$, but not its major metabolite $(F=1.62, p>0.25)$. The average amounts excreted in the urine were treatment $\mathrm{B}>$ treatment $\mathrm{C}>$ treatment $\mathrm{A}$ for both tolmetin and the major metabolite as would be expected for acidic drugs. The mean amounts of tolmetin excreted in the $0-24 \mathrm{~h}$ urine were $12.4 \mathrm{mg}(3.1 \%$ of the dose), $18.6 \mathrm{mg}(4.9 \%$ of the dose) and $13.5 \mathrm{mg}$ 


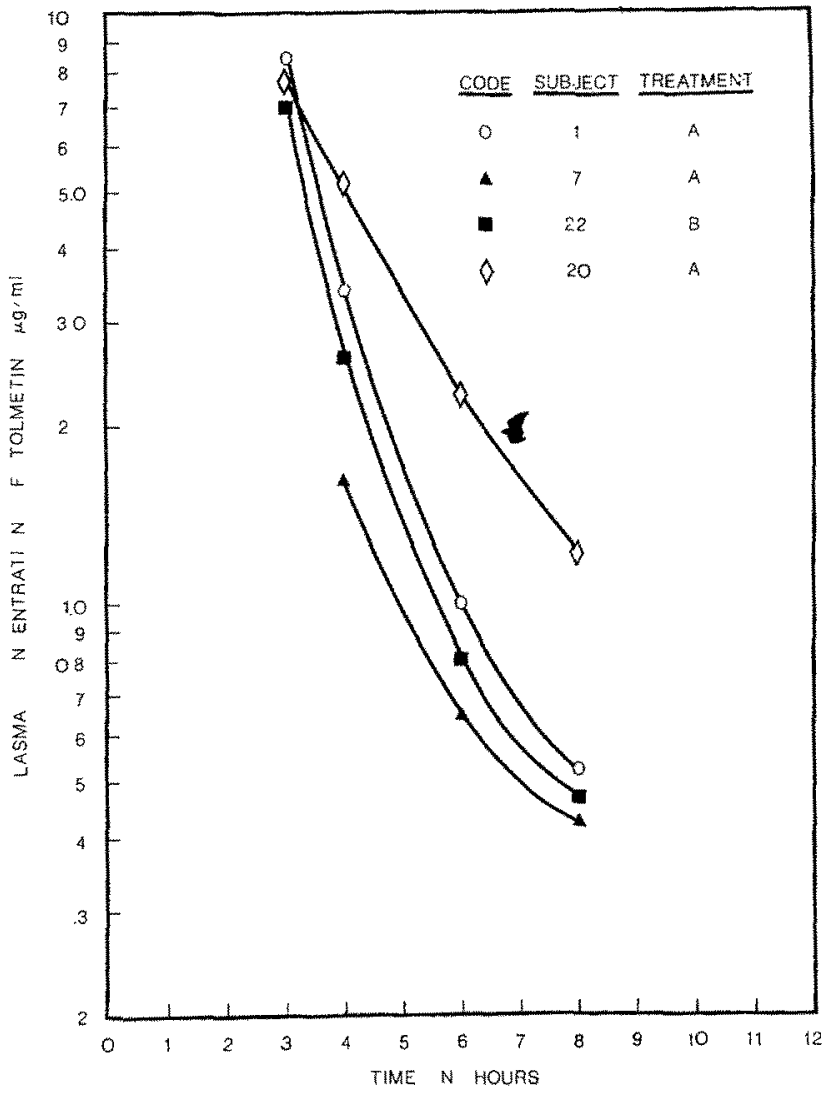

Fig. 3. Representative semilogarithmic plots of terminal plasma concentrations of tolmetin

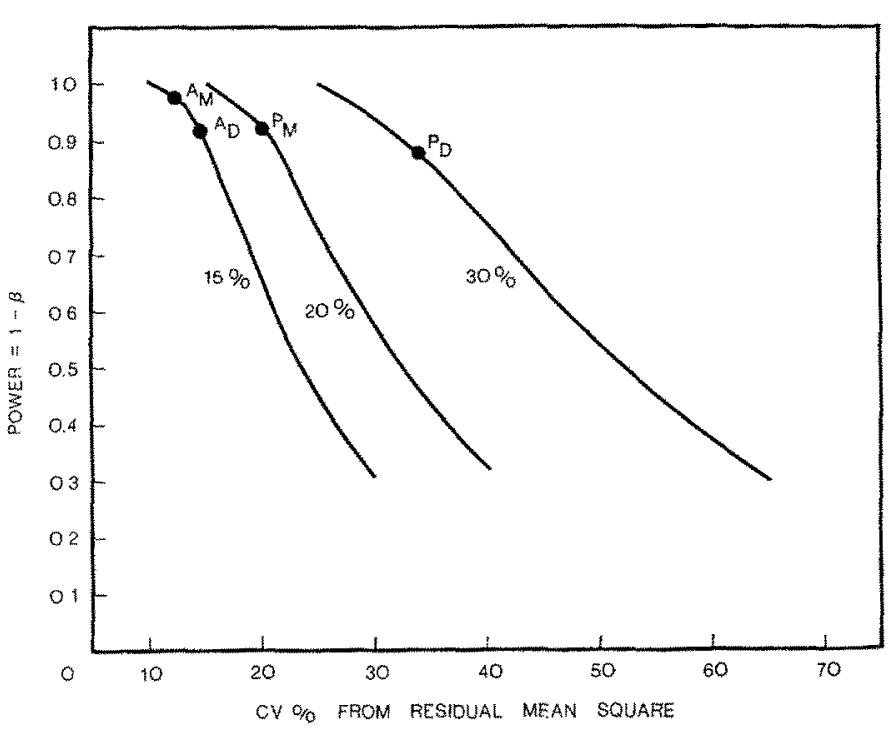

Fig. 5. Power of the analysis of variance vs. coefficient of varia tion for detecting $15 \%, 20 \%$ or $30 \%$ difference in extreme means. Key: Curves are for $15 \%, 20 \%$ and $30 \%$ difference in extreme mean. $A_{M}=$ area $0-8 \mathrm{~h}$ for metabolite; $A_{D}=$ area $0-8 \mathrm{~h}$ for tolmetin (drug) $; \mathrm{P}_{M}=$ peak plasma concentrations of metabolite; $\mathrm{P}_{\mathrm{D}}=$ peak plasma concentrations of tolmetin (drug)

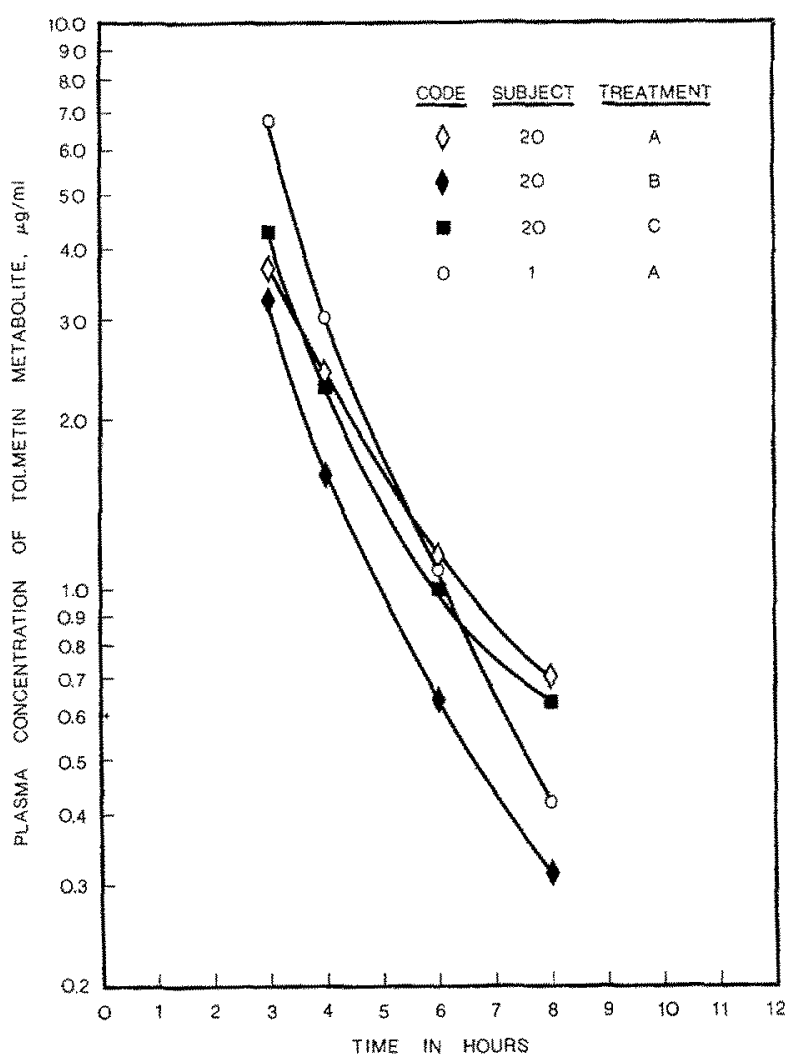

Fig. 4. Representative semilogarithmic plots of terminal plasma concentrations of the major metabolite of tolmetin

( $3.4 \%$ of the dose) for treatments $\mathrm{A}, \mathrm{B}$ and $\mathrm{C}$, respectively; the overall mean was $14.8 \mathrm{mg}(3.7 \%$ of the dose) with a range of $0.778 \mathrm{mg}$ to $50.2 \mathrm{mg}$ $(0.2 \%$ to $12.5 \%$ of the dose $)$.

The mean amounts of the major metabolite excreted in the $0-24 \mathrm{~h}$ urine were 183,207 and $212 \mathrm{mg}$, equivalent to $39.1,44.2$ and $45.3 \%$ of the dose of tolmetin for treatments $\mathrm{A}, \mathrm{B}$ and $\mathrm{C}$, respectively. The overall mean was $201 \mathrm{mg}(42.9 \%$ of the dose) with a range of $20.8 \mathrm{mg}$ to $309 \mathrm{mg}(4.4 \%$ to $66 \%$ the dose).

There were no significant differences $(0.10$ $>p>0.05)$ among the treatment mean renal clearances of tolmetin $(3.20,4.69$ and $3.49 \mathrm{ml} / \mathrm{min}$ for treatments $\mathrm{A}, \mathrm{B}$ and $\mathrm{C}$, respectively). There were no significant differences $(0.25>p>0.10)$ for treatment mean renal clearances of metabolite $(141,169$ and $164 \mathrm{ml} / \mathrm{min}$ for treatments $\mathrm{A}, \mathrm{B}$ and $\mathrm{C}$, respectively (see Table 2).

The powers of the ANOVA for detecting a $15 \%, 20 \%$ or $30 \%$ difference in extreme means of parameters obtained following the three treatments were calculated and the results are given in Figure 5. 


\section{Discussion}

There was no evidence of a significant drug-drug interaction between tolmetin and the antacid. The time to peak plasma concentration, the peak concentration, the area under the plasma concentration, time curve, and the renal clearance of tolmetin were all not significantly perturbed by the antacid. These results show that the antacid employed may be taken chronically, or as a single dose administered with tolmetin, and it will have no significant effects on the pharmacokinetics of the tolmetin.

Semilogarithmic plots of terminal plasma concentrations of both tolmetin and its major metabolite were curved (Figs. 3 and 4). This curvature is most probably due to saturable tissue-binding of the drug as has been reported by Ayres et al. (1977). This does not mean that there is anything "wrong" with the drug, but just that simple linear pharmacokinetics do not apply in calculating the apparent elimination half-life of the drug. It does mean that the reported elimination half-life values of less than one bour for tolmetin (Plostnieks et al., 1975; Cressman et al., 1975) are most probably incorrect, as the mean "true half-life" is probably in excess of $2.6 \mathrm{~h}$. It is not known whether the curvature in the semilogarithmic plot for the metabolite is a reflection of the curvature for the drug or due to nonlinearity inherent in the metabolite.

Estimation of AUC $0-\infty$ by the classical methods will not give the exact answer from tolmetin data because of the nonlinearity which exists. However, for tolmetin plasma concentrations the AUC $0-8$ was $97-98 \%$ of the estimated AUC $0-\infty$ using classical methods (Wagner, 1975) and the 6 and $8 \mathrm{~h}$ concentrations to obtain the apparent elimination rate constant. This indicates that the majority of the AUC $0-x$ resides in the AUC $0-8$, and the AUC $0-8$ can be used to conclude that there was no significant treatment effect on the amount of tolmetin absorbed.

The observation that the antacid did not significantly affect the plasma levels of tolmetin, but did significantly alter the urinary excretion of tolmetin must be attributed to two factors: (a) the antacid did not significantly affect the absorption of tolmetin; and (b) the change in such a small amount of unchanged drug excreted in the urine is significant, but is not well reflected in the plasma level data since an overall of $96.3 \%$ of the tolmetin is metabolized. This relatively small effect on excretion of unchanged drug due to treatment with antacid would be of no clinical significance.

An important consideration is the power of the analysis of variance. If the hypothesis that certain means were equal was false, a so-called type II error ( $\beta$ error) would occur if the tested hypothesis was accepted when it was false. The probability of rejecting the tested hypothesis when it was false is called the "power of the test against a specified alternative" and is denoted by $1-\beta$. For example, if $1-\beta$ $=0.8$, then the chances are 0.8 out of 1.0 of detecting the specified difference in means. Figure 5 is a plot of the power, $1-\beta$, against the coefficient of variation calculated from the residual mean square (RMS) of the ANOVA and the tables of Dixson and Massey (1957) and is specific for the number of subjects and treatments used in the present study i.e., the figure is based on the RMS having degrees of freedom, $v_{1}=2$ and $v_{2}=44$ with $\alpha=0.05$. One curve in the figure is for a $15 \%$ difference in extreme means, a second curve is for a $20 \%$ difference in extreme means, and a third curve is for a $30 \%$ difference in extreme means. To use the figure one requires a coefficient of variation listed in the last two columns of Table 2. Four examples are shown in the figure. For example, $A_{M}$ indicates that $1-\beta$ $=0.98$ where the coefficient of variation was $12.4 \%$ and Am symbolizes AUC $0-8$ for the metabolite. From Figure 5 and the coefficients of variation listed in Table 2 , one can see that one obtains a high power for a small difference $(15 \%)$ in extreme means for AUC 0-8, but for peak concentrations the difference in extreme means must be $20 \%$ or $30 \%$ to get a high power since the coefficients of variation are larger. The parameter, time to peak concentration, is associated with the highest coefficient of variation and hence the power is relatively poor. These results obtained in this study with these three parameters are consistent with those obtained in other bioavailability studies performed by the authors.

\section{References}

Ambre, J.J., Fisher, L.J.: Effect of coadministration of aluminium and magnesium hydroxides on absorption of anticoagulants in man. Clin. Pharmacol. Ther. 14, 231-237 (1973)

Ayres, J.W., Sakmar, E., Hallmark, M. R., Wagner, J.G.: Highpressure liquid chromatographic (HPLC) determination of tolmetin and its major metabolite in plasma. Res. Comm. Chem. Path. Pharmacol. 16, 475-483 (1977)

Ayres, J. W., Weidler, D.J., Sakmar, E., Wagner, I. G.: Linear and nonlinear assessment of tolmetin pharmacokinetics. Res. Comm. Chem. Path. Pharmacol. 17, 583-593 (1977)

Carson, J. R., McKinstry, D. N., Wong, S.: Benzoyl-1-methylpyrrole-2-acetic acids as anti-inflammatory agents. I. Med. Chem. 14, 646-647 (1971) 
Cressman, W. A,, Wortham, G. F., Plostnieks, I.: Absorption and excretion of tolmetin in man. Clin. Pharmacol. Ther. 19, 224-233 (1975)

Dixson, W.J., Massey, F.J., Jr.: Introduction to statistical analysis, 2nd ed., 257. New York: McGraw-Hill 1957

Gibaldi, M., Grundhofer, B., Levy, G.: Effect of antacids on $\mathrm{pH}$ of urine. Clin. Pharmacol. Ther 16, 520-525 (1974)

Gibaldi, M., Grundhofer, B., Levy, G.: Time course and dose dependence of antacid effect on urine pH. J. Pharm. Sci. 64, 2003-2004 (1975)

Herxheimer, A., Chaput de Saintonge, D. M.: Sodium bicarbonate enhances the absorption of propantheline in man. Europ. J. clin. Pharmacol. 5, 239-242 (1973)

Kostenbauder, H. B., Portnoff, J. B., Swintosky, J. V.: Control of urine $\mathrm{pH}$ and its effect on sulfaethidole excretion in humans. J. Pharm. Sci. 51, 1084-1089 (1962)

Levy, G., Leonards, J.R.: Urine $\mathrm{pH}$ and salicylate therapy. J. Amer. Med. Ass. 217, 81 (1971)

Lieberman, S. V., Wood, J.H.: Aspirin formulation and absorption rate II. J. Pharm. Sci. 53, 1492-1495 (1964)

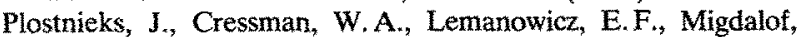
B.H., Tam, J.J.S.: Human metabolism of Tolmetin. In: Tolmetin, a new non-steroidal anti-inflammatory agent (ed. J. R. Ward), pp. 23-33. Amsterdam: Excerpta Medica 1975

Selley, M.L., Tomas, J., Triggs, E.J.: A gas-liquid chromato- graphic method for the quantitative determination of tolmetin in plasma and tolmetin and its major metabolite in urine. J. Chromatogr. 94, 135-142 (1974)

Selley, M.L., Glass, J., Triggs, E.J., Thomas, J.: Pharmacokinetics studies of tolmetin in man. Clin. Pharmacol Ther. 17, 599-605 (1975)

Sumner, D.D., Dayton, P.G., Cucinell, S.A., Plostnieks, J.: Metabolism of Tolmetin in rat, monkey, and man. Drug Metab. Dispos. 3, 283-286 (1975)

Wagner, J. G.: Fundamentals of clinical pharmacokinetics, p. 344. Hamilton, Ilinois, USA: Drug Intelligence Publications 1975

Wong, S., Gardocki, J.F., Pruss, T.P.: Pharmacologic evaluation of tolectin (tolmetin, $\mathrm{McN} 2559$ ) and $\mathrm{McN} 2981$, two antiinflammatory agent. J. Pharmacol. Exp. Ther. 185, 127-138 (1973)

Received: July 4, 1977, in revised form: September 13, 1977 accepted: September 27, 1977

Dr. John G. Wagner

Upjohn Center for Cinical

Pharmacology

The University of Michigan Medical Center

Ann Arbor, Michigan 48109, USA 